https://www.journal-imab-bg.org
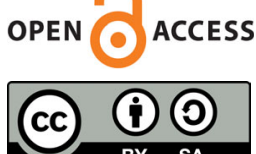

Review article

\title{
STATE OF PATIENT SAFETY CULTURE IN BULGARIA: a literature review
}

\author{
Rositsa T. Dimova ${ }^{1}$, Ilian Y. Doykov ${ }^{2}$, Lyuboslav R. Dimov ${ }^{3}$ \\ 1) Department of Health Management and Health Economics, Medical \\ University of Plovdiv, Plovdiv, Bulgaria \\ 2) Department of Otorhinolaryngology, Medical University of Plovdiv, Plovdiv, \\ Bulgaria. \\ 3) Medical student, Medical University of Plovdiv, Plovdiv, Bulgaria.
}

\begin{abstract}
:
This paper aimed to review and analysis of current literature, based on the complex evaluation of the publications in the available national and international literature, related to hospital patient safety culture. A literature review was conducted via searching the MEDLINE, PubMed, Google Scholar and Sofia Central Medical Library electronic databases. Relevant publications were also retrieved from the paper based collection at the Medical University in Plovdiv, using the "de visu" approach. "Patient safety", "safety culture", "hospital safety culture", "prevention of medical errors", "patient safety reporting system" and "medical error" served as search keywords. The study selection identified a total of 224 surveys. Finally, only 21 articles were examined and discussed in the review. The current literature review shows the need to develop and maintain a positive patient safety culture in the healthcare settings in Bulgaria. It requires amendments to the existing regulations, the introduction of uniform taxonomy, universal measuring instruments of patient safety culture and registration of medical errors in healthcare settings.
\end{abstract} culture.

Keywords: patient safety, review, patient safety

\section{INTRODUCTION:}

The history of the terms "safety" and later "safety culture" dates back to ancient times. However, the issue of safety still remains a focus of attention in our century of developed technology and industry. In a broader aspect, safety culture has a complex meaning and in the field of healthcare, it is defined as acknowledged individual and group values, concepts, perceptions, competencies and behavioral models aimed at achievement of patient safety within the healthcare system [1, 2]. In the 1990s, successful safety measures were implemented in most well developed high risk industries as aviation, nuclear energy, shipping and chemical industries. Similar approaches were also introduced to healthcare services. Patient safety is a main determinant of the quality of healthcare services. Patient safety culture is strongly related to organizational culture, specific of healthcare. Within the system culture, different professional categories (doctors, nurses, etc.) have different perceptions of patient safety [3]. Healthcare services are considered apriori safe, otherwise they would not be able to provide care and treatment to patients and hospital mortality rates would reach unacceptable rates. In the complex world of healthcare, the existence of medical errors has been acknowledged by experts all over the world for many years. However, public attention was drawn to the subject, following the report published by the Institute of Medicine, named "To err is human" [4]. Over the last couple of decades, worldwide, patient safety and improvement of quality of healthcare services have become a priority $[4,5]$. The concept of safety culture and its existence in the medical facilities is related to the process of disclosure of medical errors $[6,7]$. Identification of the basic causal factors or factors that underlie medical errors has contributed substantially to the enhancement of patient safety [8]. Worldwide experience has provided evidence that registration of medical errors and adverse events vary widely, thus creating confusion among experts, health professionals and policy makers $[9,10,11]$. The most important causal factor for it, is the lack of standardized and uniform taxonomy, related to patient safety worldwide [10]. It is true that various definitions of the basic terms - medical errors and adverse events often results in mistakes and omissions in information collection and analysis, making its comparison on a national and international level difficult $[12,13]$. The various methods for information collection, registration and patient selection and the different Reporting Systems for Patient Safety Incidence (RSPS), are among the important causal factors as well. For this reason, in order to estimate the actual incidence of medical errors and adverse events, clear, objective definitions are needed, alongside with valid measurement instruments. Plenty of examples of different organizations and different activities related to patient safety exist all over the world [14]. However, regardless of the presence of dozens of valid and standardized instruments to measure patient safety culture and the existence of different National Reporting Systems for Patient Safety (RSPS), in Bulgaria, despite recommendations by the European Union (EU), these are lacking $[7,15]$. The need to improve patient safety culture 
has to be acknowledged by everyone all over the world. It requires both: transformation of how health professionals currently care for patients and a continuous state of alert for patient safety in healthcare facilities.

\section{OBJECTIVE:}

The aim of the present study is to provide a thorough review, and critical analysis of the available specialized literature in the field of patient safety in an attempt to answer the research question whether patient safety culture exists in healthcare organizations in Bulgaria.

\section{REVIEW RESULTS:}

\section{Research strategy}

An electronic search of the MEDLINE, PubMed, Google Scholar and Central Medical Library (Medical University Sofia) databases was conducted. Paper-based issues at the Library of the Medical University in Plovdiv, were reviewed using the visual approach, with manual searches of the bibliographies of included articles and the key journals. Our strategy was to search relevant articles in two languages: English and Bulgarian and covered all studies published on the topic until now. Data screening, data extractions and data appraising of the included articles were the main steps in conducting the review.

Inclusion and exclusion criteria

Two authors (RD, ID) independently reviewed the content of each survey to identify and select studies on the topic of interest, using inclusion and exclusion criteria. Any disagreement between them was resolved in a discussion session. On the basis of inclusion and exclusion criteria, valid and reliable conclusions regarding the topic could be drawn. It was performed prior to the literature search in order to minimize the possibility of bias. Inclusion criteria: all articles relevant to the topic including keywords as "patient safety", "safety culture", "hospital safety culture", "prevention of medical error", "patient safety reporting system" and "medical error". Exclusion criteria: lack of open access to full text articles. Two languages, English and Bulgarian, were used in data searching.

The study selection identified a total of 224 surveys. Finally, 35 sources met the preliminarily specified eligibility criteria: to answer the research question of interest. The articles were classified as follows: 4 articles related to ehealth and EU legislation, 7 - to medication safety, 6 - to self-treatment with antibiotics, 6 - to legislation relating to health and safety in Bulgarian healthcare settings, $8-$ to errors in medical and dental practices and 4 - related to Management and Information Communication System Technology (ICT). At a later stage: 3 books and 3 dissertations related to patient safety as well as to the medicolegal and social consequences of errors in medical practice were included. The entire selection process design is shown in Figure 1. Finally, only 21 articles were examined and discussed in the review.

Fig. 1. Design of selection process work flow.

\section{Pub Med, Medline, Google Scholar, Central Medical Library in Medical University Sofia and Paper printed collection of Medical University Plovdiv (de visu approach)}

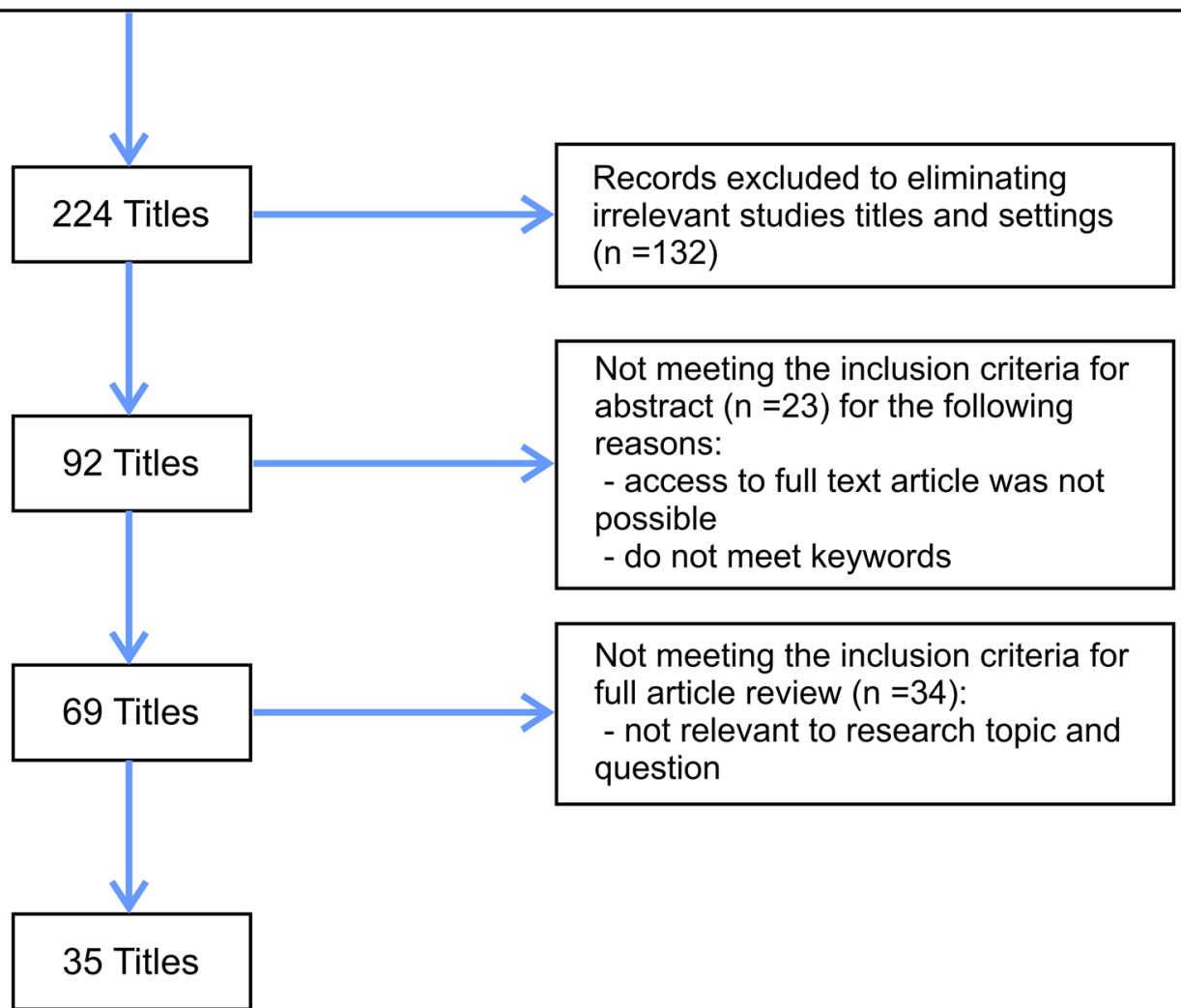


No ethics committee approval was necessary for this review.

"Primum non-nocere", or "First do no harm" is the basic ancient tenet in medical care, however, it still holds true at present. Regardless of this basic concept in healthcare, a certain risk of harm is usually accepted as nonpreventable [8]. Unfortunately, long-term experience has shown that not all human errors, including medical errors, are preventable and could be completely eliminated [5]. In Radojnova's opinion, the probability of success in medical and diagnostic procedures rarely reaches a $100 \%$. Moreover, even strict adherence to good medical practice does not always result in favorable outcomes [16, 17]. This is most likely due to the uncertainty at the entrance and the unpredictability at the exit in medical care. "Poor outcomes" of medical care not always, in fact, rarely are a consequence of "poor" medical processes or bad structure of medical care [18].

In Bulgaria, improvement of patient safety culture is not yet a priority, however, attempts have been made to draw public attention and interest towards the consequences of adverse events and errors in medical practice [7]. A number of research works have documented that speaking up for patient safety among medical professionals as well as for reporting of undesirable events or errors in medical practice is still a taboo in our country due to fear of false allegations, and unjustified prosecution and punishment. The fear of losing public image and the subsequent direct and indirect economic, marketing, medico-legal, ethical and psychological consequences should also be taken into consideration [19].

In the international literature, terms related to patient safety culture as negligence, medical error, mistake, malpractice, adverse event, adverse outcome, undesirable event, unwanted event and others often are confused and overlapping. Not rarely, different terms are used, implying the same meaning and content (World Health Organisation, Institute of Medicine, National Health Survice (NHS), Agency for Healthcare Research and Quality, Joint Commission on the Accreditation of Healthcare Organizations (JCAHO), Australian Commission for Safety and Quality in Health Care, National Patient Safety Agency.

Some Bulgarian researchers consider that the term "doctors error" is not precise and correct from the legal point of view and they offer a novel, actual definition of the term $[20,21,22]$. In other authors' opinion, harm to patients when due to imperfections of medical science as well as to individual human organism differences or objective unfavorable external factors is not an error but an innocent mistake of the medical professionals in the process of performing their duties, based on good practice protocols and medical ethics [20]. In the latter case, harm to patients is due to insufficient knowledge, negligence or overconfidence. In both described cases, "doctors errors" could be either innocent or deliberate actions or not taking actions [20]. In conclusion, these authors, although distinguishing between the two cases state that both could be classified as medical errors.

In our literature, a classification framework for medical errors has been proposed, based on their causal factors [20]. International researchers have put forward similar classification frameworks for medical errors [23]. Unfortunately, in Bulgaria, so far, serious results regarding health legislation as well as amendments to the existing health regulations in the field of this delicate issue have not been achieved [24]. According to the Bulgarian Laws, "doctors" error" is not a legal term. Only a number of authors and the Medical Audit Agency ( entitled to control providers regarding quality and patient safety) provide their own definitions of the terms medical and "doctors" errors", despite the lack of clear differentiation between the two and the fact that their meaning and content often overlap [16, 19, 24,]. Some authors based on analysis of legislation and specialized literature conclude, that no practical measures and strategies aimed at improving quality and safety of medical care have been developed [24, 25]. In our available literature, good practice results and adequate decisions regarding improvement of patient safety culture are lacking. On the contrary, positive results in this area have been achieved in other countries [22, 26]. One of our prominent authors in this field, explores the main reasons why patient safety has not yet been adopted as a priority in Bulgarian health policy. The author also proposes a number of activities to be considered from policymakers, health managers and the community. The researcher lists the most important causal factors: lack of relevant institutions, lack of structured system for collecting and analyzing data related to medical errors, existence of blame culture in hospitals and lack of systemic approach [7]. In the reviewed literature, the need for amendments to the existing regulations in order to improve legal medical expertise is stressed [16, 27]. Recommendations of: how to improve medical professionals' knowledge of deontology and how to improve the existing legal framework have been proposed [16]. Furthermore, other studies with a legal focus, stress the importance of modern methods of solving disputes between patients or their relatives and medical professional outside the courtroom for example mediation. Unfortunately, they do not offer strategies to prevent medical errors and ways to aid medical professionals to avoid malpractice suits $[22,28]$. On the other hand, some authors emphasize the positive aspects of mediation as a very useful and efficient way to resolve dispute, especially between patients and physicians/providers of health care. Mediation is very common in the USA in cases of medical malpractice suits: there only $10-15 \%$ of legal disputes reach trial and the average time spent on mediation range from 1 to 4.5 hours compared to 36 hours preparation of the attorney before the trial. On the contrary, in Bulgaria, mediation in healthcare is rare, regardless of the fact, that this model was first accepted in 2004 [28].

In international research works, a substantial amount of valid instruments to measure safety culture have been described, and various systems for patient safety reporting have been proposed [10]. In other countries, leadership in 
the field of patient safety have been introduced, focused on creating "culture of trust" and "blame-free environmental", thus promoting the concept "never accept that harm cannot be reduced" [2]. This results in continuous enhancement of patient safety in healthcare, based on the non-punishment approach, including reporting of errors alongside with proactive monitoring, incidence reporting and critical analysis [8]. Authors of the Linneus Project report that until 2015 in our country there are no: valid instruments for measurement of patient safety culture, no systems for registration of medical errors and guidelines for good medical practice [7, 19, 25, 26, 29].

Experience from other societies, similar to ours, show that much has to be done to create a positive patient safety culture [14]. However, in Bulgaria, so far, a number of research works have been conducted focused on patient safety. They offer originally developed questionnaires, unfortunately, results are not comparable to those from other countries $[19,30]$. These studies document the negative attitude of health professionals towards the introduction of PSRS and the lack of trust and support by the hospital managers in reporting medical errors. These practices and attitudes in our healthcare system could be easily explained with the prevailing blame culture and presence of personal approach instead of: leadership with patient safety priority objective“, „open communication“, „mutuality, trust and honesty“ and system approach in prevention of the medical errors [19, 30, 21]. Researchers specializing in similar areas have examined the level of knowledge of medical professionals in the field of patient safety culture as well as their perception of the importance of patient safety in modern clinical practice [30]. In the context of improving hospital patient safety culture, the author describes a number of techniques and models to assess and analyze risks related to patient safety. An algorithm has been proposed in order to identify analyze, assess and manage patient safety risks (accident probability). It is aimed at improvement of patient safety in the clinical practice [30]. Another study conducted among hospital managers document that the interviewed have a positive attitude and declare readiness to introduce the system for medical errors reporting if patients access to the system is limited [31]. Regarding patient access to ICT, hospital managers consider that patients should have the right to register complaints but should not be able to access the database [31, 32]. A useful step in the right direction was the completion of the intra-university Project No.11/2017 named: „Introduction of web-based platform for registration and assessment of the level of patient safety in the healthcare facilities and conduction of a national representative survey" [33]. The aim of the project was the improvement of patient safety culture and the quality of medical care in healthcare settings in Bulgaria. Within the frame of the project, an original conceptual framework was developed and systematic classification of the basic terms related to safety culture was proposed. The system is well adapted to the specificity of the healthcare settings in Bulgaria. The terms undesirable event and medical error are clearly defined and differentiated [33]. The results of the study describe specific medical errors and their consequences as well as their main causal factors. It also illustrates the negative impact of the lack of system for registration of medical errors. Definitions of the terms doctors' errors and medical errors are provided [25]. In a dissertation work, focused on the efficacy of the system for investigating and sanctioning medical errors, the existing system is rated as ineffective, non flexible and practically non functioning [21]. Other studies deal with the economic aspects of medical errors and their cost. One of these research works attempts to assess the additional costs related to compensations due to delivery of poor quality medical services, including medical errors [34]. A methodology for assessment of the cost of medical errors and an algorithm for their prevention are presented by Stoyanova et al. [35]. Our researchers introduce a unified information system for filing and assessing medical errors in healthcare system and offer a methodology for calculating the cost of medical malpractice claims [36]. Other publications examine patients attitudes and models of self-treatment with antibiotics as well as the attitudes of pharmacists towards dispensing antibiotics without prescription. The results indicate frequent violation of the regulations, restricting the free access to antibiotic, thus putting patients safety in danger [37, 38].

This review has some limitations. We recognize the existence of different types of biases in the process of conducting this systematic review during the selection, extraction and reporting of the studies. Time limitation and the lack of free access to ful-text relevant articles in Bulgarian and English in the investigated databases using keywords were also present. We could not claim to have covered all relevant publications as not all Bulgarian studies are available in the Electronic Databases.

\section{CONCLUSION:}

Patient safety culture is a complex multidimensional construct. In Bulgaria, its aspects need further investigation due to insufficient research in this area. In this review, an attempt is made to thoroughly analyze the current state of this issue, based on the complex evaluation of the publications in the available national and international literature. The current literature review shows the need to develop and maintain a positive patient safety culture in the healthcare settings in Bulgaria. It requires amendments to the existing regulations, the introduction of uniform taxonomy, universal measuring instruments of patient safety culture and registration of medical errors in healthcare settings. Summarizing the result, we would like to mention a number of initiatives, that should be encouraged in the Bulgarian healthcare system:

- Creating a work environment, where patient safety culture is the main priority and among the most important organizational objectives;

- Introduction of information and communication system (ICT) for registration of and assessment of adverse events and medical errors (PSRS) at a national level;

- Introduction of patient safety programs;

- Introduction of instruments to measure patient 
safety culture in the existing regulations as an integral part of the required accreditation standards.

\section{Acknowledgements:}

The present study was made possible thanks to the University Project from the Medical University of Plovdiv No. 11/2017 named: "Development and Implementation of a web-based platform for registration and evaluation of the level of patient safety culture in the healthcare system in Bulgaria and conduction of a national representative study."

\section{REFERENCES:}

1. Sexton JB, Thomas EJ, Helmreich RL. Error, stress, and teamwork in medicine and aviation: cross sectional surveys. BMJ. 2000 Mar 18;320(7237):745-9. [PubMed] [CrossRef]

2. Sorra J, Nieva VF. Hospital survey on patient safety culture. Agency for Healthcare Research and Quality publication no. 04-0041. Rockville, MD: AHRQ, September 2004.

3. Hindle D, Haraga S, Radu CP, Yazbeck AM. What do health professionals think about patient safety? $J$ Public Health. 2008 Apr;16(2):87-96. [CrossRef]

4. To Err is Human: Building a Safer Health System. Kohn LT, Corrigan JM, Donaldson MS, editors. Washington (DC): National Academies Press (US); 2000. [PubMed]

5. Makary MA, Daniel M. Medical error-the third leading cause of death in the US. BMJ. 2016 May 3;353: i2139. [PubMed] [CrossRef]

6. Soul BM. 1. Patient safety. In: Basic concepts of Infection Control. [Bulgarian version] IFIC. 2011. 17p. [Internet]

7. Popova M. Developing the patient safety issue in Bulgaria. Health Economics and Management. 2007 1: 3-11. [in Bulgarian].

8. Ralston JD, Larson EB. Crossing to safety: transforming healthcare organizations for patient safety. $J$ Postgrad Med. 2005 Jan-Mar;51(1): 61-7. [PubMed]

9. Australian Commission on Safety and Quality in Healthcare, Measurement for Improvement. Toolkit. Commonwealth of Australia. 2006. [Internet]. 2006.

10. The Health Foundation. Research scan: Measuring safety culture. February 2011. [Internet]

11. Leape LL. Error in medicine. JAMA. 1994 Dec 21;272(23):1851-7.
[PubMed]

12. Levinson W, Gallagher TH. Disclosing medical errors to patients: a status report in 2007. CMAJ. 2007 Jul 31;177(3):265-7. [PubMed] [CrossRef]

13. Leape LL, Berwick DM, Bates DW. What practices will most improve safety? Evidence-based medicine meets patient safety. JAMA. 2002 Jul;288(4):501-7. [PubMed]

14. Mitevska L, Donev D. Patient safety at secondary level of healthcare in the republic of Macedonia - what can be learned from the experiences of other countries. Medicus. 2015; 20(1):90-7.

15. Klemp K, Zwart D, Hansen J, Hellebek T, Luettel D, Verstappen W, et al. A safety incident reporting system for primary care. A systematic literature review and consensus procedure by the LINNEAUS collaboration on patient safety in primary care. Eur J Gen Pract. 2015 Sep;21 Suppl:3944. [PubMed] [CrossRef]

16. Radoynova D. Doctors errors and deontology. Social medicine. 2015;2:41-3 [in Bulgarian]

17. Radoynova D. Professional recklessness in medicine (Doctors' errors). Color Print. 2014 [in Bulgarian]

18. Moss F. Risk management and quality of care. Qual Health Care. 1995 Jun;4(2):102-7. [PubMed]

19. Popova M. [Conceptual Model for Building a Patient Safety System in Hospitals.] [dissertation]. Medical University Sofia. 2012.pp.8-35 [in Bulgarian]

20. Liychkova M, Hristozova E, Lesinska M, Karadjova R, Stoykova M. [Medical ethics.] Medical University - Plovdiv. 1999. pp.23-35 [in Bulgarian]

21. Spasov Sv. [Deontological, medico-legal and social aspects of errors in medical practice.] [dissertation]
Medical University Plovdiv. 2014. pp 20-55. [in Bulgarian]

22. Sharkova M. [Current policies and protocols in case of occurrence of adverse events in medical facilities.] [in Bulgarian] Reports of Proceedings of IVth National Conference "Bioethics and Biolegal-Modern Practices and Polices". October 2016. pp.67-76. [Internet]

23. Science of improvement: How to improve. Institute for Healthcare Improvement. 2011. [Internet]

24. Petrova Z. [Criteria for doctors and medical errors - in search of a consensus definition.] [in Bulgarian] CredoWeb. November 2014. [Internet]

25. Petrova Zl. Medical Audit as a method to manage risks in healthcare. Scripta Scientifica Medica. 2011; 43 (7):211-15.

26. Petrova Zl, Popova M. [The role of Medical Audit Agency in the process of registration of medical errors.] Social Medicine. 2010;4:24-26 [in Bulgarian]

27. Radoynova D. [Doctors errors, from a medico- legal point of view.] Steno Varna Press; 2013. pp.8-38 [in Bulgarian]

28. Mavrov M, Iliev Y, Sharkova M, Spasov S. Mediation in healthcare unknown method for alternative dispute resolution. Bulgarian Medicine. 2014; 4(1):22-6.

29. Godycki-Cwirko M, Esmail A, Dovey S, Wensing M, Parker D, Kowalczyk A, et al . Patient safety initiatives in Central and Eastern Europe: A mixed methods approach by the LINNEAUS collaboration on patient safety in primary care . Eur J Gen Pract. 2015 Sep;21 Suppl:62-8.. [PubMed] [CrossRef]

30. Radeva N. [Study of factors, influencing patient safety in intense therapy for acute pancreatitis.] [dissertation] Medical University Sofia. 
2011. pp.74-124 [in Bulgarian]

31. Stoyanova R, Dimova R, Raycheva R. The Survey of Health Care Managers' Attitude towards the Implementation of Information and Communication System for the Registration of Medical Errors. Economics and Business. 2013; 24:135-140. [CrossRef]

32. Raycheva R, Stoyanova R. Information system for registration and economic assessment of medical errors - health managers readiness to introduce. Scripta Scientifica Medica. 2011; 43(7):217-19.

33. Scientific Project No.HO-11/ 2017 titled: [Development and Implementation of web-based platform for registration and evaluation of the level of patient safety culture in healthcare system in Bulgaria and conduction of a national representative study.] Medical University Plovdiv. 2017. [in Bulgarian]

34. Stoyanova R. [Medical errors an extra financial burden for health insurance companies or a new niche at the insurance market in Bulgaria. Health insurance market - current state, expectations, vision and priorities to manage transformation.] X-th National conference, November 3-4 2011. Conference papers and presentations- Sofia: Avangard Prima, 2012; 259-265 [in Bulgarian]

35. Stoyanova RG, Raycheva RD, Dimova RT. Economic aspects of medical errors. Folia Med (Plovdiv). 2012 Jan-Mar;54(1):58-64. [PubMed] [CrossRef]

36. Stoyanova R, Raycheva R,
Hospital information system for medical malpractice - registration and evaluation, ISHIMR 2011, Proceedings of the Fifteenth International Symposium for Health Information Management Research, 8-9 September 2011. Zurich, Switzerland. 549-50.

37. Dimova R, Stoyanovà R, Raycheva R, Doikov I. [Research on the population attitude and behavior patterns - purchase of regulated antibiotics without a prescription.] Farmacia. 2012; 59(1-4):49-54. [in Bulgarian]

38. Stoyanova R, Dimova R, Raycheva R. Sale of regulated antibiotics without prescription - Research on the pharmacists' attitudes and patterns of economic behavior. Trakia Journal of Sciences. 2012; 10(4):71-5.

Please cite this article as: Dimova RT, Doykov IY, Dimov LR. State of patient safety culture in Bulgaria: a literature review. J of IMAB. 2018 Apr-Jun;24(2):2024-2029. DOI: https://doi.org/10.5272/jimab.2018242.2024

Received: 26/03/2018; Published online: 11/06/2018

Address for correspondence:

Rositsa Tsvetanova Dimova,

Department of Health Management and Health Economics, Medical University of Plovdiv,

15a, Vasil Aprilov Blvd. 4002 Plovdiv, Bulgaria

E-mail: ros_dimova@yahoo.com, 